\title{
The Gamification Design for Affordances Pedagogy
}

Wilawan Inchamnan ${ }^{1, *}$, Jiraporn Chomsuan ${ }^{2}$

${ }^{1}$ College of Creative Design \& Entertainment Technology, Dhurakij Pundit University, Bangkok, Thailand

${ }^{2}$ College of Innovation Business and Accountancy, Dhurakij Pundit University, Bangkok, Thailand

\begin{tabular}{l} 
A R T I C L E I N F O \\
\hline Article history: \\
Received: 12 May, 2021 \\
Accepted: 22 June, 2021 \\
Online: 10 July, 2021 \\
\hline Keywords: \\
Gamification \\
Affordance \\
Growth Mindset \\
Design method \\
Affordances Pedagogy \\
Motivation and Engagement \\
\end{tabular}

\section{Introduction}

In the 21 st century, there is extensive research on growth mindset and intrinsic motivation in learning. The constructs of mindset and motivation are important for educators to determine the impact on student learning and outcomes [1]. Understanding the two constructs, mindset and motivation, and the relationship between them is necessary as it provides insight into student motivation and drive. Gamification is a tool that can increase and promote user motivation, especially in education. The educational concept requires that teaching and learning activities are more fun and interesting [2]. Today, learner engagement is still a challenge in the education system. Design is employed in education to increase the student desire to focus on the educational task [3], as an affordance mindset. Educational games and various forms of edutainment have gained more attention in the discipline of learning and teaching strategies. Educators believe learning can be enhanced through play and fun [4]. The increasing motivation to learn may affect the learnerì affordances. An affordance concerns

"Corresponding Author:Wilawan Inchamnan, E-mail: wilawan.inn@dpu.ac.th the possible actions that an item offers while learning. The term affordance is a somewhat ambiguous term [5]. and affordance could be improved in terms of its ability to influence learning outcomes.

Learner can conduct their learning lives using advanced technology that engender an affordance behavior mindset. The mindset is a crucial factor in leaner motivation. Affordances are a core opportunity for action [6]. A mindset can change the attitude to learning in the education system, which represents a step in the right direction.

This paper reviews several recent gamification studies that focus on growth mindset and motivation. The theoretical frameworks of Affordance Mindset and Motivation reflect how they are applied in educational gamification. The research design is divided into two parts. The first focuses on the engagement elements related to the gamified classroom activities. The gamification strategies are then designed by using the mindset factors and learner characteristics. Then the gamification affordances design method is applied through points, badges, 
leaderboards and ranks in gamification activities for the pedagogy strategies.

\section{Literature Review}

\subsection{Mindset}

The mindset is a set of both conscious and unconscious human beliefs, which relates to how humans view what they consider to be their personality. Mindset can be divided into two types, Fixed Mindset and Growth Mindset. These mindsets refer to the way people think about the nature of intelligence and learning. People with a growth mindset value effort, tend to set learning goals (e.g., mastery)rather than performance goals (e.g., grades), and attribute failure to lack of effort rather than lack of ability [7]. Learnersì mindsets can be influenced by school-based activities to help improve academic outcomes [7] through motivation and engagement.

\subsection{Motivation and Engagement}

Motivation and engagement indicate passion and emotional involvement in learning activities [8]. Engagement permits meaningful learning, which includes the quality of student effort, student interaction and their immersive experiences [8]. Some research divided engagement into three dimensions: behavioral, emotional, and cognitive engagement [3].

\subsection{Motivation}

Motivation is an abstract construct used to explain people behavior. The behavior represents the basis for peopleis actions, desires, and needs. Motivation can be named as oneis behavioral direction, or what justification a person to want to repeat a behavior [9]. Motivation can be allocated into two different types known as intrinsic (internal) motivation and extrinsic (external) motivation [10].Intrinsic motivation is the desire to seek new things and new challenges, to analyze one's abilities, to observe and to gain knowledge [11]. It is driven by interest or enjoyment in the task itself and exists within the individual rather than relying on external factors or the desire for reward. Intrinsic motivation arises from within the individual, just as the idea of an affordance draws attention to a possible action [12]. Extrinsic motivation mentions to the performance of an activity to attain a desired consequence and is the opposite of intrinsic motivation [11]. Extrinsic motivation is the type of motivation that comes from outside the individual and often involves rewards such as trophies, money, social recognition, or praise. In education, motivation is a major cause of differences in student learning outcomes, considered a possible predictor of a student's academic performance; students with high academic motivation are more likely to succeed academically [13]. Students who are intrinsically motivated are more likely to be curious and inquire about the process, focusing on the task itself rather than just the outcome. In contrast, students who are extrinsically motivated are more concerned with the outcome (e.g., grades, prizes) than with the process of completing the task itself [14]. Game activities could encourage player experiences, which is called immersive engagement. Engagement also influences peopleis adoption. Behavior usage is how frequently or for what purpose the behavior is used while behavior adoption is the degree to which the behavior is utilized. Psychological outcome is a measure of effort. The level of effort is influenced by emotional engagement (pleasure, excitement, and persistence), behavioral engagement (effort), cognitive engagement (attention, reflection), and learning performance (perceived competence, perceived improvement) [3]. The student can repeat desired behaviors by reinforcement providing. Reinforcement incentives people into two forms of motivation. The first one is intrinsic motivation that refers to engage in behaviors for enjoyment, challenge, pleasure, or interest [5]. Then, the extrinsic motivation can engage in an activity to earn an external reward when learner is motivated to perform their behavior [1].

\subsection{Engagement}

Engagement in the extent to which a learner connects with the gaming environments and indicates a positive psychological state of mind when so doing [15]. Games' activities provide immediate feedback, which is more effective and efficient than traditional learning strategies. Gamification strategies can encourage the learner to be acquire experience during play. Game experiences drive personal change and transformation by generating an attitude of acceptance about the challenge, motivation to achieve, and constant innovation by simulation. Simulation encourages the participant to immerse themselves in learning [16]. Adaptation is the process by which strategies are moderated by engagement. Adaptation is a consequence of activities and events that are enhanced, developed, and implemented. Success in learning depends on the learner's desire to learn, which is known as behavioral intention [17]. Learners can change their behavior as a result of motivation. Engagement may encourage behavior. Usage can be influenced by behavioral assumption. The focus of usage behavior is on specific activities performed using specific sources of information. These include general knowledge acquisition, learning, and the pursuit of purposes [18].

\subsection{Gamification Affordances}

As a concept, affordance provides a useful bridge to explain the interplay between the artefact and the human user [5]. Gamification elements could provide a thematic evaluation of subsequent formulations of the term affordance. This is the method designed to provide a preliminary overview of how the notion of affordance can be interpreted. The figure 1 show the direct perception of affordances for the user along with a consideration of the usersì skills. The researcher refers to the "flow channel"as a linear function on a plane with skills and challenges as axes. An increase in the learner's skills is due to learning, and an increase in the challenges of performing a task is due to novelty [19]. The pedagogy design may keep the two in balance between challenges and skills. Subjects experienced Flow when they first encountered a task with a high balance between skills and challenges [20].Skills is due to learning and an increase in the challenges of performing tasks [21], which relate to an affordance. The design of the 
pedagogy allows for a practical mapping flow onto the gameplay. The approach enhances the player's interaction with the game elements and provides useful insights into the learner's skills [21]. The next section presents gamification affordance strategies including points, badges, and leaderboards.

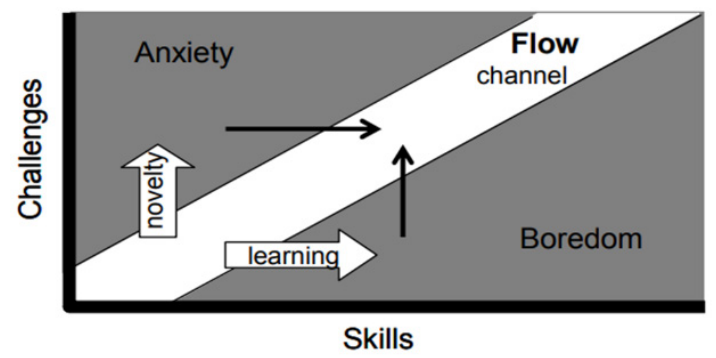

Figure 1:The Flow Channel

\subsubsection{Points}

Point is the activity outcome. Game point can trigger and reinforce situational awareness competencies. Points can provide information about the playeris progressive such as response times, correct answers, and the procedures followed during play. The awarding of points is connected to behaviors that require crucial competencies [22].The competencies can develop as a training tool for learning goals [23].

This paper aims to design affordance mindset processes through the player data. The affordance for learning is measured by questionnaire questions regarding learnersì sense of pride and community acceptance. The satisfaction of basic psychological needs (competence, autonomy, and relatedness [24]), is a fundamental requirement for being autonomously motivated. Competence refers to the experience of success by fulfilling challenging tasks and gaining mastery within an environment [25] and is reflected by the number of points scored.

\subsubsection{Badges}

Badges reflect performance results. Digital badges indicate the achievements or skills acquired while playing the game. These badges are collected and displayed to the other players [25]. Gamification elements are used to encourage performance and skill acquisition, which are the desired learning outcomes.

\subsubsection{Leaderboards}

The most-used game element is leaderboard that refers to a ranking board of the players in a competitive event. The leaderboard is to illustrate player where they are ranked in a gamified system. Leaderboardsì mechanic can be employed in various ways to offer goals and to increase motivation [26]. Leaderboard ranking can motivate players to compete, which increases participation [27] and facilitates comparison and competition.Leaderboard is the basic elements that make up games that combined to deliver a system of mastery to end users [28].

\subsection{Cognition}

Cognition refers to the mental processes involved in the acquisition of knowledge and understanding. These cognitive processes include thinking, knowing, remembering, judging, and problem solving [29]. Cognitive processes affect every aspect of life, from school to work, to relationships. Some specific uses for these cognitive processes include the following.

- $\quad$ Learning New Things that require being able to take in new information and form new memories. The learner makes connections with other things that they already know.

- The formation of memories is a major topic in the field of cognitive psychology. Memories refer to how people remember, what they remember, and what they forget, and reveal much about how cognitive processes work.

Making decisions means making judgments about things you have experienced and processed. This may involve comparing new information with previous knowledge or integrating new information with new knowledge before making a decision [30]. Behavioral action refers to use, i.e. the fact that it is used, or habit. Relationships have been found between adoption, post-adoption variables, and usage behavior in the post-adoption process. Continued use based on experience and satisfaction in the postadoption process represents high quality use [31]. Post-adoption, each individual is engaged in change behaviors to varying degrees. In this context, several factors may influence the relationships between adoption and post-adoption variables [31].

\subsubsection{Positive Feedback}

Positive feedback is a game mechanism. This mechanism is designed to accelerate or enhance ongoing output [32]. Gamification can be applied to stimuli of increasing intensities through intrinsic rewards and feedback. The user-centered design activities require an interactive feedback. The learning activity feedback is determined by peopleis motivation and cognitive mindset.

\subsubsection{Growth Mindset}

The term mindset refers to implicit beliefs that have been shown to influence the thoughts and actions of individuals [33]. A learner's mindset has been shown to influence his motivation and academic performance [34], [35]. Growth mindset type means that a learner can improve his talents and abilities through effort. Growth mindset belief is a type of intelligence that can be improved through hard work and the use of strategies [36]. Growth Mindset can be generated through motivation and achievement [37], [38], could promote learner's engagement.

A growth mindset helps learners improve their skills and knowledge over time, and mindset research studies the power of such beliefs in influencing human behavior [39]. Mindset is a soft skill of great importance [40]. For example, athletes are driven by success and can realize their potential through effort, practice, and instruction. In the education system, some research has shown that students with a growth mindset can greatly improve their success and achievement [41]. 


\subsection{The Growth Mindset Stimulus Model}

According to the previous research, the figure 2 illustrates the gamification model, which encourages learner to conduct their learning by using gamification elements. The learning behavior refers to the taking steps in the right direction guideline. Gamification activities conceptual model can be influenced by gamified activities [42]. The growth mindset is fostered by the positive feedback through cognition and motivation. The motivation can be stimuli by competency and leaderboard. The cognition could be influence by level [42].

The figure 2 shows the gamification workflow for growth mindset processes that influence the positive feedback and growth mindset by gamified activities. The learneris growth mindset is measured through feedback, level, motivation, their position on the leaderboard, and their competencies. The model shows the gamification activities can increase the likelihood of achieving the learning objectives by motivating students to learn. This illustrates the relationship between the stimulus activities and growth mindset processes [43]. Game activities can encourage the learner to practice their skills and their position on the leaderboard can enhance their pride and social acceptance. Motivation and cognition can enhance their performance through positive feedback and higher scores (GPA).

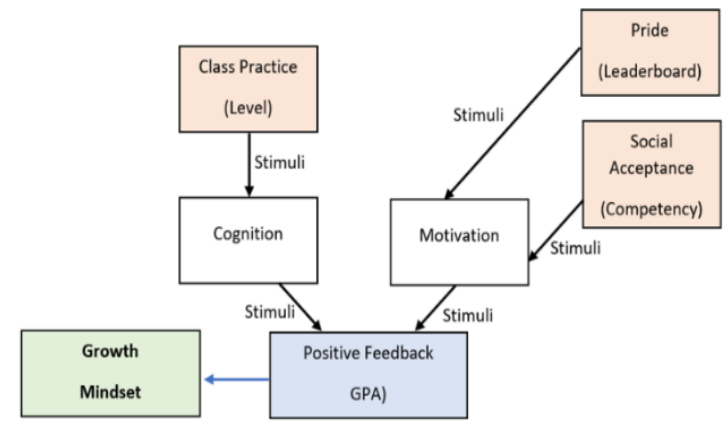

Figure 2: The Growth Mindset Stimulus Model [42]

\section{Methodology}

Having reviewed a scholarly source on a topic concerning mindset then mindset questionnaire is developed to classify participants into a different mindset characteristic. This research aims to link the mindset factors and gamification elements. The experiment design aims to cluster the mindset criteria and determine the relationships between the factors and the learning outcomes. The data collection uses a mindset questionnaire to facilitate comparisons with learner subjects. The pedagogy design gathers the university lecturer for the strategiesì class activity. The advisor experiences help to map the teaching or pedagogy style with gamification elements. Figure 3 illustrates the processes of data evaluation.

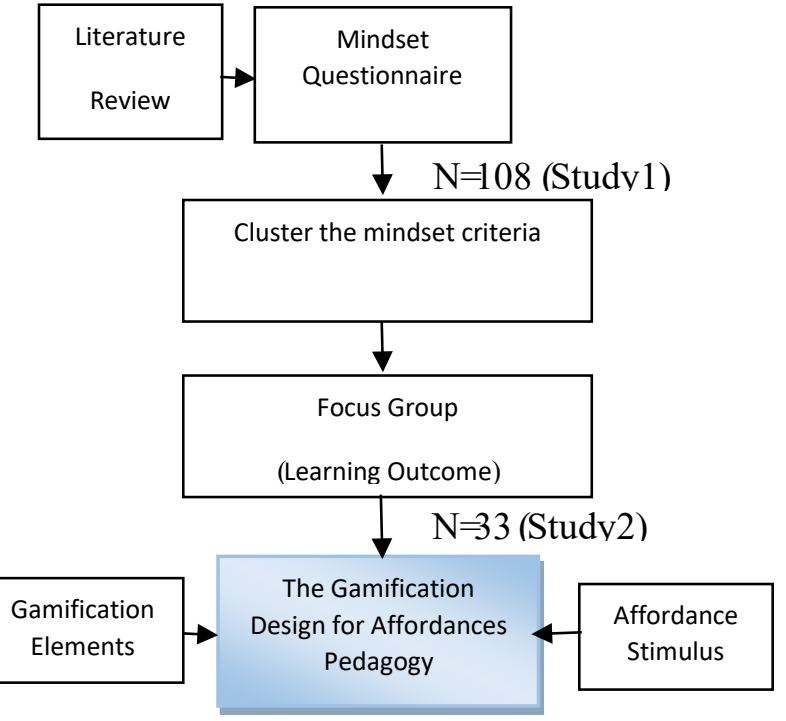

Figure 3:The Methodology of the gamification design for affordances pedagogy

\subsection{Participants}

Study1: According to factors finding, the participants in this study were 108 university Dhurakij Pundit University students. Participants included $72 \%$ from the Business faculty, $24 \%$ from the Creative Design faculty and $4 \%$ from the Journalism faculty all aged between 18 and 23. All participants in this study were volunteers. The average GPA was 3.55 .

Study2: Then, the pedagogy design participants in this study were 33 university lecturers, randomly. The questionnaire design used the factors from the first findings. The average of experiences was 13 years. Normally, their teaching style were lecture and practical (50:50). They preferred to use gamification in the classroom and showed the score or progress to their student.

\subsection{Clustering the mindset criteria:Factor Analysis (Study1)}

This study uses the factor analysis. The mindset measures by questionnaires survey. The students may respond to questions about their opinions, which are all associated with the latent fix and growth variable mindset as below.

- Fix1:It is difficult for my intelligence/level of intelligence to change.

- Fix2:There are certain activities / subjects that I cannot be good at.

- Fix3: I think people do not have to try to do what they are capable of.

- Fix4: I can always learn new things, but I do not think that learning can increase my intelligence.

- Fix5:I am frustrated to see that people can do better than me.

- Fix6:If I have try something new and fail, I am not good at it. 
- G1:I believe I can develop in all areas, albeit a little.

- G2:When I do something wrong, I feel that I would learn more from it.

- G3:I feel great when people see that I am good / talented, that means I am successful.

- G4:I am inspired by successful people.

- G5:I feel that I can help others to be successful.

- G6:If I try something new and fail, I want to repeat it until I can.

\subsection{The Pedagogy Design (Study2)}

The design process aims to link the pedagogical design and gamification elements and this paper focuses only on the factors affecting the mindset. The conceptual model can be employed in future work. The model can apply to the pedagogical context design includes the pedagogy plan.

The second findings from the university lectures show the relationship between factors.

- G1:The learnerìs skills can develop

- G2:Learnerìs practicing in the classroom

- G3:The level of learnerìs activities during learning

- G4-1:lecturerìs Comment for lesson activities individual

- G4-2:lectureris Comment for lesson activities to all of students

- Gamification:The class activities during learning

- Learn for smart:- Learn new things can increase the intelligence.

\section{Results}

\subsection{Clustering the mindset criteria}

The relationship of each variable to the underlying factor is expressed by the factor loading. The result of factor analysis, which deals with indicators of mindset, with twelve variables (opinions) and four resulting factors is shown below. Factor loadings can be interpreted like standardized regression coefficients, so the opinion in response 1 (Fix 1) has a correlation of 0.72 with Factor 1. Five others, responses 2,3,4,5, and 6 (Fix 2,3,4,5,6), all representing fixed-attitude characteristics, are also associated with Factor 1. Based on the loading of the variables, the finding points high on factor 1, it could be considered as "Fixed Mindset".

However, opinions on questions 9 and 10 (Growth3 and 4), have high factor loadings on the other factor, Factor 2 . They seem to indicate an external stimulus; that is, students are driven by other people, so Factor 2 would be classified as "Exogenous growth mindset." Similarly, Factor 4, is constituted by an answer of Growth 5 and 6 showing that students have positive feelings whenever they help others, which is an external stimulus, hence Factor 4 would also be regarded as "Exogenous growth mindset".

Table 1:Component Analysis

\begin{tabular}{|c|c|c|c|c|}
\hline & \multicolumn{4}{|c|}{ Rotated Component Matrix ${ }^{a}$} \\
\hline & \multicolumn{4}{|c|}{ Component } \\
\hline & 1 & 2 & 3 & 4 \\
\hline Fix1 & .721 & -.353 & .071 & .170 \\
\hline Fix6 & .708 & .174 & -.121 & -.193 \\
\hline Fix5 & .690 & .235 & -.206 & -.221 \\
\hline Fix2 & .675 & -.091 & -.105 & -.077 \\
\hline Fix3 & .673 & -.246 & .091 & .106 \\
\hline Fix4 & .611 & .131 & .060 & -.243 \\
\hline G3 & .072 & .784 & .178 & .011 \\
\hline G4 & -.077 & .638 & .328 & .221 \\
\hline G2 & -.231 & .164 & .827 & .081 \\
\hline G1 & .106 & .185 & .796 & .070 \\
\hline G6 & -.107 & .021 & .176 & .853 \\
\hline G5 & -.167 & .496 & -.040 & .647 \\
\hline \multicolumn{5}{|c|}{$\begin{array}{l}\text { Extraction Method: Principal Component Analysis. } \\
\text { Rotation Method: Varimax with Kaiser Normalization. }\end{array}$} \\
\hline
\end{tabular}

Opinions on questions 7 and 8 (Growth 1 and 2) have strong factor loadings to Factor 3. Students agreed they are likely to do anything as a result of intrinsic motivation, thus Factor 3 is regarded as îEndogenous growth mindsetï.

Table 2:KMO test

\begin{tabular}{|c|c|c|}
\hline \multicolumn{2}{|c|}{ KMO and Bartlett's Test } & \multirow[b]{2}{*}{.730} \\
\hline \multicolumn{2}{|c|}{ Kaiser-Meyer-Olkin Measure of Sampling Adequacy. } & \\
\hline \multirow{3}{*}{$\begin{array}{l}\text { Bartlett's Test of } \\
\text { Sphericity }\end{array}$} & Approx. Chi-Square & 292.755 \\
\hline & df & 66 \\
\hline & Sig. & .000 \\
\hline
\end{tabular}

The Kaiser-Meyer-Olkin test (KMO-Table 2) is a measure of how appropriate the data are for factor analysis. The KMO value in this study was .730 , which indicates that the sampling is appropriate. Bartlett's test is performed before applying factor analysis to cheque whether the data reduction technique can reasonably compress the data. In this study, the test statistic ChiSquare was 292.755 and the corresponding p-value was 0.000 , which is less than the significance level $(0.05)$. Thus, the data are suitable for factor analysis.

In column labelled (table3) " Extraction Sums of Squared Loadings. The" Total" column shows the Eigenvalues for each factor extracted which higher than 1. The second column "\%of Variance" indicates the variance is explained by each factor (or component). The "Cumulative \%"column shows the percentages of the total variance explained by the factors $(62.418 \%)$. 
Table 3:Total Variance Explained

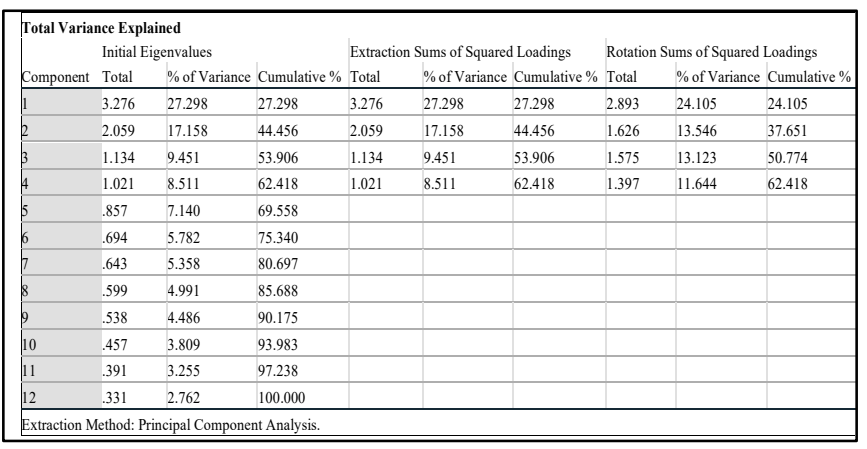

\subsection{Learning Outcome: Mindset Assessment Processes}

The results (Table 4) show that learning outcomes have a positive relationship with a fixed mindset ((Sig, .008)Fix3: Try to do what they are capable of doing. Fix 4: Learn new things, but I don't think learning can increase my intelligence).

Fix3 refers to the affordances of learning that learners believe they can develop in all areas, even if only a little (Growth Mindset: G1). The results show a significant relationship between Fix3 and G1 (.016). Affordance of Learning is also positively related to Growth Mindset (sig..001)that the learner believes they will learn more if they do something wrong (G2). Having a Fixed Mindset has a positive influence on $\mathrm{G} 4$, which refers to the learner being inspired by successful people (Sig. .000).

Table4 refers to what learners think about intelligence. They love to learn new things, but intelligence is fixed and cannot be increased by learning. The results show significant relationships between Fix4 and G1, G2, G3, and G4 (sig..025,.013,.000,.002).

Table 4: Chi-Square tests

\begin{tabular}{|l|c|c|c|}
\hline Variable & Value & df & $\begin{array}{l}\text { Asymptotic } \\
\text { Significance (2- } \\
\text { sided) }\end{array}$ \\
\hline GPA and Fix3 & $32.692 \mathrm{a}$ & 16 & .008 \\
\hline GPA and Fix4 & $26.695 \mathrm{a}$ & 16 & .045 \\
\hline G1 and Fix3 & $30.486 \mathrm{a}$ & 16 & .016 \\
\hline G1 and Fix4 & $28.788 \mathrm{a}$ & 16 & .025 \\
\hline G2 and Fix3 & $31.970 \mathrm{a}$ & 12 & .001 \\
\hline G2 and Fix4 & $25.368 \mathrm{a}$ & 12 & .000 \\
\hline G3 and Fix4 & $38.382 \mathrm{a}$ & 12 & .000 \\
\hline G4 and Fix3 & $50.059 \mathrm{a}$ & 16 & .002 \\
\hline G4 and Fix4 & $37.716 \mathrm{a}$ & 16 & \\
\hline
\end{tabular}

Having a Growth Mindset means believing in skill development, having a desire to learn more, seeing others, and being inspired by successful people. The mindset can promote the fixed mindset, which refers to how people think about the nature of intelligence and learning.

The findings (table5)show the positive relationship between $\mathrm{G} 1$ and G2. The lectures believe that the students can develop and practice in the classroom (Sig. .015). The pedagogy design such as practical tasks (G1)will encourage with comment or feedback (G4) during the activities (Sig. .033, .026).

The level design for learneris activities is positive impact on the feedback (G4)(Sig. .028) and Gamification strategy (Sig. .045). The class activities during learning such as gamification can encourage learners in terms of the new things can increase the intelligence (Sig. .039).

Table 5:ANOVA Tests (The lecture participants)

\begin{tabular}{|l|c|c|c|c|}
\hline \multicolumn{1}{|c|}{ Variable } & $\begin{array}{c}\text { Sum of } \\
\text { Squares }\end{array}$ & $\begin{array}{c}\text { Df } \\
\text { Between } \\
\text { Groups }\end{array}$ & F & Sig. \\
\hline G1 and G2 & .742 & 1 & 6.576 & .015 \\
\hline G1 and G4-1 & .970 & 1 & 5.010 & .033 \\
\hline G1 and G4-2 & 1.227 & 1 & 5.471 & .026 \\
\hline G3 and G4-1 & 1.478 & 2 & 4.036 & .028 \\
\hline Gamification and G3 & 3.976 & 2 & 3.436 & .045 \\
\hline $\begin{array}{l}\text { Gamification and learn } \\
\text { for smart }\end{array}$ & 3.480 & 2 & 3.625 & .039 \\
\hline
\end{tabular}

The results show in the table 6 that include the activities in the classroom. The participants illustrate the teaching experience to catch up the studentsì attention. The advisor experiences help to map the teaching or pedagogy style with gamification elements.

Table 6:Means comparison

\begin{tabular}{|l|c|c|}
\hline \multicolumn{1}{|c|}{ Variable } & Mean & Std.deviation \\
\hline Gamification & $4.36 / 5$ & .603 \\
\hline The feedback of progress & $4.33 / 5$ & .816 \\
\hline $\begin{array}{l}\text { The percentage level of } \\
\text { progress(100) }\end{array}$ & 37.33 & 29.49 \\
\hline $\begin{array}{l}\text { The Practical activities } \\
\text { The percentage of practical } \\
\text { activities(100) }\end{array}$ & $5.85 / 5$ & .364 \\
\hline $\begin{array}{l}\text { Inborn Intelligence } \\
\text { Learning the New things can } \\
\text { improve the intelligence }\end{array}$ & $4.06 / 5$ & .924 \\
\hline $\begin{array}{l}\text { Time in the Activities } \\
\text { Time for Activity/each (minute) }\end{array}$ & 41.66 & .747 \\
\hline
\end{tabular}




\begin{tabular}{|l|c|c|}
\hline Quest in the Activity & $3.96 / 5$ & .728 \\
\hline $\begin{array}{l}\text { Time for Quest/each activity } \\
\text { (minute) }\end{array}$ & 44.54 & 17.781 \\
\hline Social media feedback & $3.60 / 5$ & 1 \\
\hline Reward for the activity & $4.15 / 5$ & .618 \\
\hline $\begin{array}{l}\text { Percentage for reward/each } \\
\text { activity (100) }\end{array}$ & 15.64 & 12.36 \\
\hline Comment for individual & $4.69 / 5$ & .466 \\
\hline Comment for all of students & $4.54 / 5$ & .505 \\
\hline
\end{tabular}

\section{The Gamification Design for Affordances Pedagogy}

From the previous study that map to the results in this study, the finding shows the relationship between factors. The significance of fixed mindset measures was positive impact through the growth mindset (Fig 4.). According to the research background and findings, the gamification mechanics can helps develop deeper insights into the capacity for pedagogy design. The findings support the ideas to develop the optimal psychology or flow theory [19] to suggests a remarkable activity in lesson plan. The gamification elements including points, badges, and leaderboards can derive herhis optimal experience [21]. For instance, the level and point can motivate people for engagement. An individualis capacity to concentrate will impact their ability to experience flow [21].

\subsection{The Gamification Elements}

The design process aims to link the pedagogical design and gamification elements and this paper focuses only on the factors affecting the mindset. The conceptual model can be employed in future work. The model can apply to the pedagogical context design includes the promotion of tasks in each faculty, increasing motivation and encouraging desirable learning behavior. Data are collected through classroom observations and stimulated recall interviews. The core characteristics of growth mindset pedagogy include focus on process, mastery orientation, persistence, and individual student support [44].

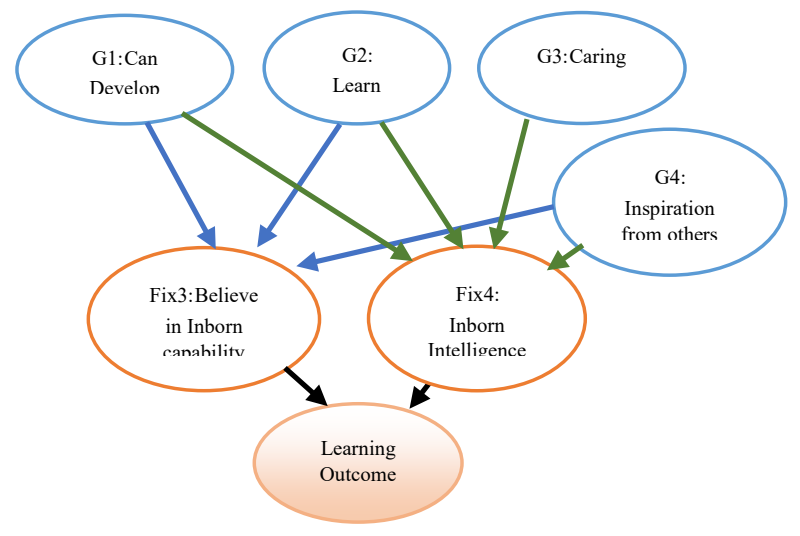

Figure 4:The relationships between factors
According to figure2, figure 5 shows the stimulus model for a growth mindset through motivation activities. The growth mindset factors are the stimuli, which can influence the learnerìs affordances.

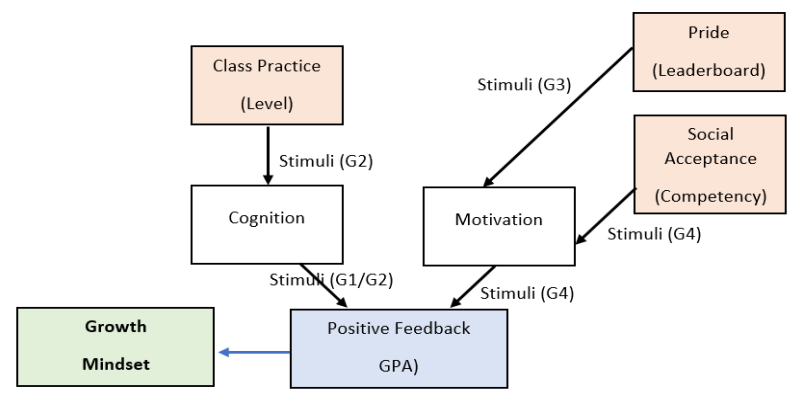

Figure 5:The Conceptual Gamification Affordances Design Model

\subsection{The Affordances Pedagogy}

The table 7 shows the findings that include the flow and pedagogy elements. These methods refer to the lecturersì experiences (Study 2) and studentsì feedback (Study 1). The gamification design for affordances pedagogy examines the literature review in terms of affordance, motivation and gamification. The research background aims to design the pedagogy elements below:

- Class assignment

- Quiz

- Group discussion

- Discussion

- Case study

- Play game

The pedagogy elements focus on the engagement that enable a practical mapping flow onto gamification. The approach enhances the studentis interaction with the gamification elements such as points, badges, and leaderboard.

Table 7:The pedagogy elements of flow and gamification design (Adopted from Jones [45]).

\begin{tabular}{|ll|l|}
\hline \multicolumn{2}{|c|}{ Element of Flow } & \multicolumn{1}{c|}{ Manifestation in Pedagogy Elements } \\
\hline 1. & $\begin{array}{l}\text { Task that we can } \\
\text { complete }\end{array}$ & $\begin{array}{l}\text { Class Assignment:The feedback of progress } \\
\text { during class } \\
\text { Game element: Point }\end{array}$ \\
\hline 2. & $\begin{array}{l}\text { Ability to concentrate } \\
\text { on task }\end{array}$ & $\begin{array}{l}\text { Quiz (test): The feedback of progress or show } \\
\text { the score } \\
\text { Game element: Point }\end{array}$ \\
\hline 3. & Task has clear goals & $\begin{array}{l}\text { Group Discussion:Quest in the Activity with } \\
\text { friends and lecturer } \\
\text { Game element: Badges }\end{array}$ \\
\hline 4. & $\begin{array}{l}\text { Task provides } \\
\text { immediate feedback }\end{array}$ & $\begin{array}{l}\text { Class Assignment: Comment for } \\
\text { individual/Comment for all of students }\end{array}$ \\
\hline
\end{tabular}




\begin{tabular}{|ll|l|}
\hline & & Game element:Leaderboard \\
\hline 5. & $\begin{array}{l}\text { Deep but effortless } \\
\text { involvement }\end{array}$ & $\begin{array}{l}\text { Discussion:social media/browsing the internet } \\
\text { Game element:Leaderboard }\end{array}$ \\
\hline $\begin{array}{l}\text { 6. } \\
\text { Exercising a sense of } \\
\text { control over their } \\
\text { actions }\end{array}$ & $\begin{array}{l}\text { Case Study:The Practical activities/The } \\
\text { percentage of practical activities around 50\% } \\
\text { per class } \\
\text { Game element: Badges }\end{array}$ \\
\hline 7. & $\begin{array}{l}\text { Concern for self } \\
\text { disappears during } \\
\text { flow, but sense of } \\
\text { self is stronger after } \\
\text { flow activity }\end{array}$ & $\begin{array}{l}\text { Play game:The activity provides for a class } \\
\text { environment as a simulation of life that refers } \\
\text { to gamification such as reward, point and } \\
\text { leader board in the class activity } \\
\text { Game element: Badges, point and leader }\end{array}$ \\
\hline 8. & $\begin{array}{l}\text { Sense of duration of } \\
\text { time is altered }\end{array}$ & $\begin{array}{l}\text { Class Assignment: Time in the Activities/Time } \\
\text { for Activity and Time for case study for each } \\
\text { activity around 40-45 minute } \\
\text { Game element:Leaderboard }\end{array}$ \\
& \multicolumn{2}{|l}{}
\end{tabular}

\section{Discussion/Conclusion}

Gamification design for affordances pedagogy focuses on engagement that provides a practical mapping flow to gamification activities during instruction. This approach could enhance student interaction through points, badges, and a leaderboard. A learning mindset could be created using motivation and affordance pedagogy. Affordance refers to points, badges, leaderboards and ranks in gamification elements. This research aimed to determine the affordance mindset factors of gamification interactive systems. The results show the relationships between factors that lead to desired learning outcomes.In accordance with Sailer, M., Homner, L. examined research topic "The Gamification of Learning: a Metaanalysis", the meta-analysis supports the claim that gamification of learning works because the results showed significant, positive effects of gamification on cognitive, motivational, and behavioral learning outcomes [46]. Similarly, there is a large body of work that clearly shows that incorporating gamification into the instructional process can lead to better student learning outcomes and helps to increase student achievement [47]-[50]. The findings derived from the current research could be used in a gamification affordances design method. The use of the model could help to improve the learner's affordances. The pedagogical guide could encourage the learner in the classroom. Engagement enables meaningful learning, which includes the quality of student effort, student interaction, and their immersive experiences during activities. The framework idea is a theoretical construct used to shape pedagogy and learner behavior. It represents the reasons for learners' actions, desires, and needs during instruction. Future research could test and revise the gamification design for the pedagogy of affordances.

\section{References}

[1] B.Ng, îThe neuroscience of growth mindset and intrinsic motivation, ̈̈ Brain Sciences, 8(2), 20, 2018, doi: 10.3390brainsci8020020.

[2] G.P. Kusuma, E.K. Wigati, Y. Utomo, L.K.P. Suryapranata, îAnalysis of gamification models in education using MDA framework,ï Procedia Computer Science, 135, 385ó392, 2018, DOI: 10.1016/j.procs.2018.08.187.
[3] C. Silpasuwanchai, X. Ma, H. Shigemasu, X. Ren, îDeveloping a comprehensive engagement framework of gamification for reflective learning, $\ddot{1}$ in Proceedings of the 2016 ACM Conference on Designing Interactive Systems, 459ó472, 2016,doi: 10.1145/2901790.2901836.

[4] K. Rapeepisarn, K.W. Wong, C.C. Fung, M.S. Khine, îThe relationship between game genres, learning techniques and learning styles in educational computer games, in in International conference on technologies for E-learning and digital entertainment, 4976́508, 2008, doi: 10.1007/978-3-540-697367_53.

[5] S. Harwood, N. Hafezieh, î́Affordanceì-what does this mean?,ï in 22nd UKAIS Annual Conference, St Catherineìs College Oxford, UK, 4th-5th April 2017, 2017.

[6] T. McClelland, îThe mental affordance hypothesis,ï Mind, 129(514), 401ó 427, 2020, doi: 10.1093/mind/fzz036.

[7] S.K. Patrick, E. Joshi, îSet in Stoneï or îWilling to Growì? Teacher sensemaking during a growth mindset initiative,i Teaching and Teacher Education, 83, 156ól 67, 2019, doi: 10.1016/j.tate.2019.04.009.

[8] R.S. Alsawaier, îThe effect of gamification on motivation and engagement,ï The International Journal of Information and Learning Technology, 2018, doi: 10.1108/IJILT-02-2017-0009.

[9] A.J. Elliot, îApproach and avoidance motivation and achievement goals,ï Educational Psychologist, 34(3), 169ól 89, 1999, doi: 10.1023/A:1009009018235.

[10] M.R.Lepper, J.H.Corpus, S.S. Iyengar, îIntrinsic and extrinsic motivational orientations in the classroom: Age differences and academic correlates., Journal of Educational Psychology, 97(2), 184, 2005, doi: 10.1037/00220663.97.2.184.

[11] R.M.Ryan, E.L.Deci, îlntrinsic and extrinsic motivations:Classic definitions and new directions,ï Contemporary Educational Psychology, 25(1), 54ó67, 2000, doi: 10.1006/ceps.1999.1020.

[12] J. Tranquillo, M. Stecker, îUsing intrinsic and extrinsic motivation in continuing professional education,i Surgical Neurology International, 7(Suppl 7), S197, 2016, DOI: 10.4103/2152-7806.179231.

[13] F.A.Hodis, L.H.Meyer, J.McClure, K.F. Weir, F.H.Walkey, îA longitudinal investigation of motivation and secondary school achievement using growth mixture modeling.,ï Journal of Educational Psychology, 103(2), 312, 2011, doi: $10.1037 / \mathrm{a} 0022547$

[14] P.R. Clinkenbeard, îMotivation and gifted students: Implications of theory and research,ï Psychology in the Schools, 49(7), 622ó630, 2012, doi: 10.1007/978-981-13-3021-6_15-1.

[15] D. Sharek, E. Wiebe, îMeasuring video game engagement through the cognitive and affective dimensions,ï Simulation $\backslash \&$ Gaming, 45(4ó), 569ó 592, 2014, doi: 10.1177/1046878114554176.

[16] A. Ahmed, M.J.D. Sutton, îGamification, serious games, simulations, and immersive learning environments in knowledge management initiatives,ï World Journal of Science, Technology and Sustainable Development, 2017, doi: 10.1108/WJSTSD-02-2017-0005.

[17] F.D.Davis, Perceived usefulness, perceived ease of use, and user acceptance of information technology. MIS Q., 319ò 340, 1989, doi: 10.2307/249008.

[18] What is Usage Behavior. (Access March, 31 2021) https:/www.igiglobal.com/dictionary/usage-behavior/71901, 2021.

[19] M. Csikszentmihalyi, Play and intrinsic rewards, Springer: 135ó153, 2014, doi: 10.1007/978-94-017-9088-8_10.

[20] M.Csikszentmihalyi, M.Csikzentmihaly, Flow: The psychology of optimal experience, Harper l\& Row New York, 1990, doi: 10.1080/00222216.1992.11969876.

[21] B. Cowley, D. Charles, M. Black, R. Hickey, îToward an understanding of flow in video games, ̈̈ Computers in Entertainment (CIE), 6(2), 1ó27, 2008, doi: $10.1145 / 1371216.1371223$ 
[22] E.Kuindersma, J.van der Pal, J.van den Herik, A.Plaat, îBuilding a game to build competencies,ï in International Conference on Games and Learning Alliance, 140́24, 2017, DOI: 10.1007/978-3-319-71940-5_2.

[23] P. Wouters, E.D. der Spek, H. Van Oostendorp, îCurrent practices in serious game research: A review from a learning outcomes perspective,ï GamesBased Learning Advancements for Multi-Sensory Human Computer Interfaces: Techniques and Effective Practices, 2320́250, 2009, DOI: 10.4018/978-1-60566-360-9.ch014.

[24] R.M. Ryan, E.L. Deci, îSelf-determination theory and the facilitation of intrinsic motivation, social development, and well-being.,ï American Psychologist, 55(1), 68, 2000, doi: 10.1037/0003-066X.55.1.68.

[25] O. Perski, A. Blandford, R. West, S. Michie, îConceptualising engagement with digital behaviour change interventions: a systematic review using principles from critical interpretive synthesis,ï Translational Behavioral Medicine, 7(2), 254ć267, 2017, doi:10.1007/s13142-016-0453-1.

[26] M.K. Pedersen, N.R. Rasmussen, J.F. Sherson, R.V. Basaiawmoit, îLeaderboard effects on player performance in a citizen science game,ï ArXiv Preprint ArXiv:1707.03704, 2017.

[27] R.Farzan, J.M.DiMicco, D.R. Millen, C.Dugan, W.Geyer, E.A.Brownholtz, îResults from deploying a participation incentive mechanism within the enterprise, $i$ in Proceedings of the SIGCHI conference on Human factors in computing systems, 563ó572, 2008, doi: 10.1145/1357054.1357145.

[28] G.Zichermann, J.Linder, îGamification revolution,ï 2013.

[29] A.P.A. STYLE, îGUIDE TO THE 6TH EDITION PUBLICATION MANUAL OF THE AMERICAN PSYCHOLOGICAL ASSOCIATION.Ï

[30] R.R. Irwin, Cognition, Springer:65ó78, 2002.

[31] K. Park, îlnnovative product usage behavior in the post-adoption process,ï ACR Asia-Pacific Advances, 1998.

[32] K.A. Abdel-Sater, îPhysiological positive feedback mechanisms,ï Am J Biomed Sci, 3(2), 145ól 55, 2011, ; doi: 10.5099/aj110200145.

[33] R. Ronkainen, E. Kuusisto, K. Tirri, îGrowth mindset in teaching: A case study of a Finnish elementary school teacher,ï 2019, DOI: 10.26803/ijlter.18.8.9.

[34] P. Bouvier, E. Lavoué, K. Sehaba, îDefining engagement and characterizing engaged-behaviors in digital gaming,ï Simulation $\ \&$ Gaming, 45(4ó), 491ó 507, 2014, DOI: $10.1177 / 1046878114553571$.

[35] K. Cherry, îPositive reinforcement and operant conditioning,ï VeryWell Mind, 2018.

[36] G.Norman, J.Norcini, G.Bordage, Competency-based education:milestones or millstones?, 2014, doi: 10.4300/JGME-D-13-00445.1.

[37] C.M.Mueller, C.S. Dweck, îPraise for intelligence can undermine childrenis motivation and performance.,ï Journal of Personality and Social Psychology, 75(1), 33, 1998, doi: 10.1037/0022-3514.75.1.33.

[38] E. OiRourke, E.Peach, C.S. Dweck, Z.Popovic, îBrain points: A deeper look at a growth mindset incentive structure for an educational game, $\ddot{i}$ in Proceedings of the third (2016)acm conference on learning@ scale, 41ó50, 2016, doi: 10.1145/2876034.2876040.

[39] R.P.French II, îThe fuzziness of mindsets: Divergent conceptualizations and characterizations of mindset theory and praxis,ï International Journal of Organizational Analysis, 2016, doi: 10.1108/JJOA-09-2014-0797.

[40] A.Derler, Growth Mindset Culture, Harvard Business Review, July 23.2018.

[41] C.S. Dweck, D.S. Yeager, îMindsets: A view from two eras,ï Perspectives on Psychological Science, 14(3), 481ó496, 2019, doi: $10.1177 / 1745691618804166$.

[42] W. Inchamnan, J. Chomsuan, îGamification Workflow for Growth Mindset Processes, ï in 2020 18th International Conference on ICT and Knowledge Engineering (ICT $\ \& \mathrm{KE}), \quad 1606, \quad 2020, \quad$ DOI: 10.1109/ICTKE50349.2020.9289879.
[43] A.Hochanadel, D. Finamore, others, îFixed and growth mindset in education and how grit helps students persist in the face of adversity,ï Journal of International Education Research (JIER), 11(1), 47ó50, 2015, DOI:10.19030/JIER.V11I1.9099.

[44] I. Rissanen, E. Kuusisto, M. Tuominen, K. Tirri, îln search of a growth mindset pedagogy: A case study of one teacherìs classroom practices in a Finnish elementary school,ï Teaching and Teacher Education, 77, 204ó213, 2019, doi: 10.1016/j.tate.2018.10.002.

[45] M.G.Jones, îCreating Electronic Learning Environments: Games, Flow, and the User Interface.,i 1998.

[46] M. Sailer, L. Homner, The gamification of learning: A meta-analysis, 2020, DOI: 10.1007/s10648-019-09498-w.

[47] J.C. Burguillo, îUsing game theory and competition-based learning to stimulate student motivation and performance,ï Computers $\backslash \&$ Education, 55(2), 566ó675, 2010, DOI: 10.1016/j.compedu.2010.02.018.

[48] C.-H. Chen, C.-H. Chiu, îEmploying intergroup competition in multitouch design-based learning to foster student engagement, learning achievement, and creativity,ï Computers I\& Education, 103, 99ól13, 2016, doi: 10.1016/j.compedu.2016.09.007.

[49] A. Dominguez, J. Saenz-de-Navarrete, L. De-Marcos, L. Fernández-Sanz, C. Pagés, J.-J. Martinez-Herráiz, îGamifying learning experiences: Practical implications and outcomes,ï Computers $\backslash \&$ Education, 63, 380ó392, 2013, doi: 10.1016/j.compedu.2012.12.020.

[50] W. Frkacz, îAn empirical study inspecting the benefits of gamification applied to university classes,ï in 2015 7th Computer Science and Electronic Engineering Conference (CEEC), 135ól39, 2015, DOI: 10.1109/CEEC.2015.7332713. 